\title{
Indicadores de mobilidade urbana em Campina Grande, PB
}

\author{
Urban mobility indicators in Campina Grande, PB
}

Laura Lins Dantas Albuquerque ${ }^{1 *}$, Hermes Alves de Almeida²

\begin{abstract}
RESUMO
A Mobilidade Urbana é a movimentação de pessoas e de mercadorias, o que requer políticas públicas de planejamento. Nesse contexto, procurou-se estabelecer os principais indicadores da mobilidade urbana de Campina Grande, sendo essas determinações os objetivos principais. Utilizaram-se dados de mobilidade urbana da referida cidade e de outras, disponíveis no IBGE, Superintendência de Trânsito e Transportes Públicos de Campina Grande (STTP), DENATRAN e outros, além de coleta, in loco, aplicando-se questionários semi-estruturados aos usuários do transporte coletivo da STTP. Os principais resultados evidenciaram que o transporte coletivo é a principal opção de mobilidade para as classes de baixa renda, embora haja intensa migração para o uso de motocicletas. Com elevados indicadores de congestionamentos mais da metade dos usuários de ônibus migraram para motocicleta, comprometendo, a sustentabilidade. Nas pequenas cidades, o quantitativo de motos já supera o de carros. Sugerem-se ações de educação no trânsito, sinalização e corredores que resultem não somente na segurança viária, mas na diminuição de custos sociais com acidentes, melhoria na acessibilidade e mobilidade dos pedestres.
\end{abstract}

Palavras Chave: Transporte Coletivo; Veículos motorizados; Congestionamento; Acidentes

\begin{abstract}
Urban Mobility is the movement of people and goods, which requires planning public policies. In this context, an attempt was made to establish the main indicators of urban mobility in Campina Grande, with these determinations being the main objectives. Urban mobility data from that city and others, available at the IBGE, Superintendence of Transit and Public Transport of Campina Grande (STTP), DENATRAN and others, were used, in addition to collection, in loco, applying semi-structured questionnaires to the STTP public transport users. The main results showed that public transport is the main mobility option for the low-income classes, although there is an intense migration towards the use of motorcycles. With high indicators of congestion and more than half of bus users migrated to motorcycles, compromising sustainability. In small towns, the number of motorcycles already exceeds that of cars. Educational actions in traffic, signage and corridors are suggested that result not only in road safety, but in reducing social costs with accidents, improving accessibility and pedestrian mobility.
\end{abstract}

\footnotetext{
${ }^{1}$ Prof ${ }^{a}$ Ms, Unifacisa, Prog. Pós-graduação em Desenvolvimento Regional, UEPB, Campina Grande, PB.* E-mail: lauralins.adv@gmail.com

${ }^{2}$ Prof $^{\circ}$ Dr, Universidade Estadual da Paraíba (UEPB), Departamento de Geografia, Campina Grande, PB.
} 
Keywords: Collective Transport; Motor vehicles; Congestion; Accidents.

\section{INTRODUÇÃO}

O espaço urbano é dinâmico e passa por modificações para se adequar as necessidades, anseios e contradições da sociedade. Os impactos negativos dos sistemas de mobilidade urbana, baseados em soluções privadas e motorizadas de transportes, são cada vez mais perceptíveis e um dos maiores problemas sociais e urbanos, questões essas que têm consequência direta sobre a mobilidade urbana (LITMAN, 2006; MARICATO, 2013).

A mobilidade urbana é a base fundamental do planejamento urbano e da qualidade de vida da população. As condições de deslocamento das pessoas e mercadorias nos centros urbanos impactam pelas gerações de externalidades negativas, cujas distorções refletem, especialmente, nos congestionamentos, na segregação do espaço urbano e na emissão de gases poluentes, podendo ser entendida a partir de uma relação dialética com a questão ambiental (CRAICE, 2015).

Neste contexto, as cidades estão sendo planejadas muito mais para mobilidade de carros, em vez de pessoas. A urbanização, a partir da segunda metade do século XX, modificou substancialmente os espaços urbanos, com alterações no volume das edificações, dos modos de implantação, das técnicas utilizadas e das disposições e dimensões dos espaços livres (Negrão e Silveira, 2016). Por isso, os pedestres perdem espaço nas calçadas rebaixadas, para servir de estacionamento para carros e motocicletas.

As políticas públicas voltadas ao deslocamento urbano estão integradas, em sua maior parte, a priorização do transporte individual. No novo modelo urbano, deve-se almejar que elas tenham ações adequadas de mobilidade coletiva para a integração do deslocamento do cidadão com o desenvolvimento socioeconômico (SILVA, FREIRE e SANTOS, 2020). 
A mobilidade urbana reflete o grau de movimento possível da cidade, promovendo a interação entre o deslocamento de pessoas e bens, aonde o transporte em si é uma atividade necessária à sociedade, por possibilitar a circulação de pessoas e mercadorias e, por consequência, a realização de atividades socioeconômicas (VASCONCELLOS, 2005; MARTINS, VASCONCELOS e SALLES, 2017).

A Lei da Mobilidade Urbana ( $\mathrm{n}^{\circ} 12.587 / 12$ ) delega aos municípios a tarefa de planejar e executar a política de mobilidade urbana, ou seja, transfere a responsabilidade para os municípios a gestão do transporte coletivo, do sistema viário e de circulação (BRASIL, 2012).

A circulação interfere diretamente no modo como as pessoas e negócios se relacionam para incrementar a economia, pelo consequente aumento do consumo, de bens e serviços, na articulação de políticas de transporte e no desafio da mobilidade urbana (CARVALHO, 2016).

O marco de aglomerações urbanas no território brasileiro iniciou a partir de 1960, quando a política nacional de desenvolvimento urbano, implantou as regiões metropolitanas e os polos secundários nas cidades, como suporte a projetos de descentralização urbana nos níveis nacional e regional (MOURA e PEGO, 2016).

O Brasil é um país com avançado processo de transição urbana, com reflexo na expansão da frota de veículos facilitada, principalmente, pela maior oferta de crédito (Ojima et al., 2013), em virtude disto, a quantidade de veículos ultrapassou 110 milhões de unidades, em agosto de 2021 (DENATRAN, 2021), com crescimento desde 2010, quando o número era de 64,8 milhões. (IBGE, 2018).

Mesmo que o carro resolva, em parte, o deslocamento, o aumento do transporte individual motorizado e a consequente redução de viagens no transporte público vêm contribuindo para o crescimento no número de acidentes de trânsito com vítimas, além dos intermináveis congestionamentos, como também, da elevada quantidade de emissão de poluentes veicular (CARVALHO, 2011).

As cidades não foram planejadas para oferecer serviços a essa nova demanda. Para que o espaço urbano seja produtivo é necessário que haja mobilidade de pessoas, de 
objetos, de ações, de representações, de ideias, de mercadorias, dentre outros. Assim sendo, os espaços urbanos são como "amálgamas" de elementos que se movem, interagem e porque criam espaços diferenciados, cada qual com sua função e com a sua relação social (LÉVY, 2001).

Neste contexto, houve a necessidade de se estabelecer os principais indicadores da mobilidade urbana de Campinha Grande, PB, sendo essas determinações os objetivos principais.

\section{MATERIAIS E MÉTODOS}

\section{Caracterização da Área de Estudos}

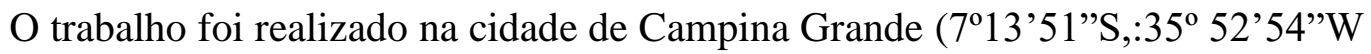
e $512 \mathrm{~m}$ ), localizada na região geográfica imediata e intermediária de Campina Grande, PB (Figura 1).

Figura 1. Vista aérea da cidade de Campina Grande, PB

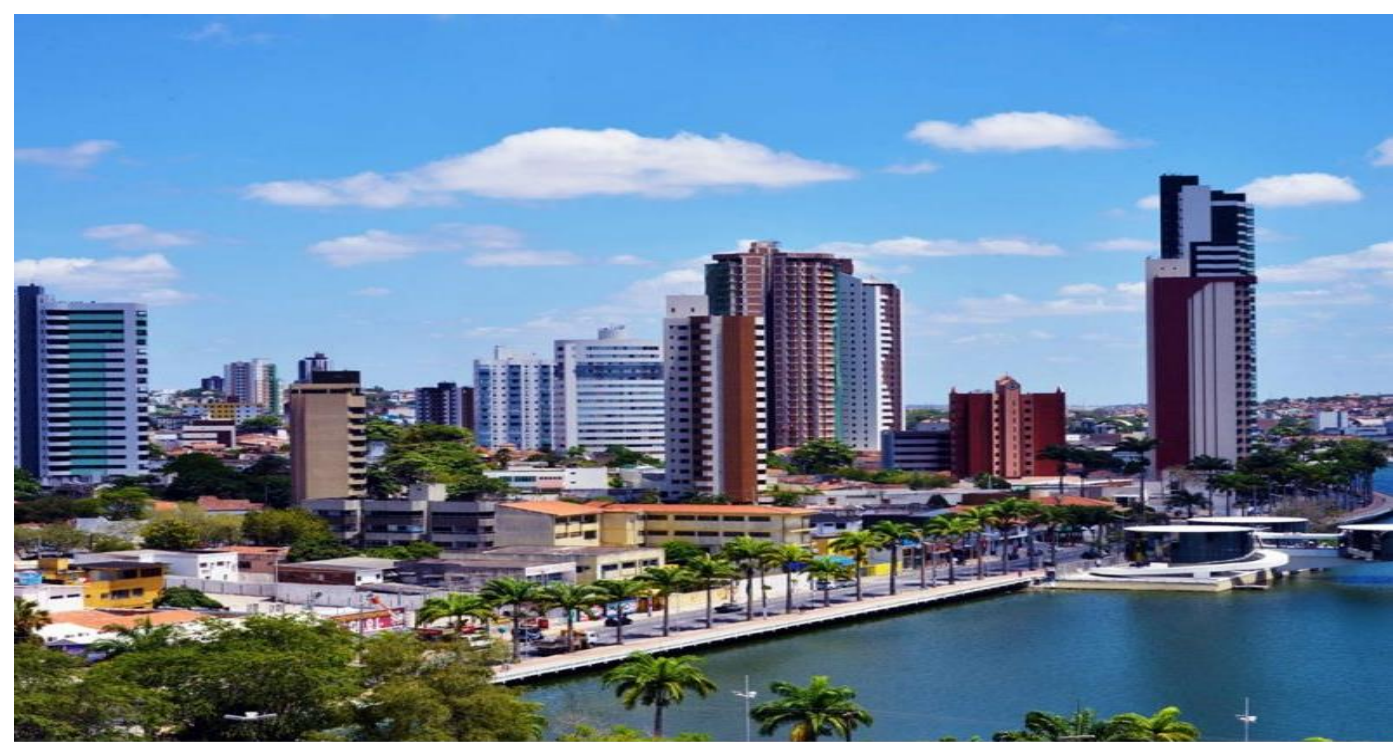

Fonte: https://www.google.com/search?q=Cidade+de+Campina

O município de Campina Grande possui uma extensão territorial de 595,5 km² e uma população estimada, em 2018 , de 410.332 habitantes e densidade demográfica de $656,4 \mathrm{hab} / \mathrm{km}^{2}$. 
A Região Geográfica Imediata de Campina Grande tem grande influência política e econômica no recorte geográfico do "Compartimento da Borborema", representado por quarenta e sete municípios e uma população superior a um milhão de habitantes.

O número médio de veículos que circula, atualmente, na cidade de Campina Grande é da ordem 200 mil e esse quantitativo representa um acréscimo de 133\%, quando se compara com o do ano de 2004, cuja consequência é uma piora gradativa no trânsito na cidade.

A Região Metropolitana de Campina Grande (RMCG), criada pela Lei Complementar Estadual no 92/2009 e sancionada dia 11 de dezembro de 2009, é formada por dezenove (19) municípios. Campina Grande (Figura 1) que é a segunda cidade mais populosa do Estado da Paraíba e ocupa uma posição de destaque como polo tecnológico da América Latina.

\section{Procedimentos metodológicos de coleta de dados}

Os métodos de coletas de dados foram executados a partir dois procedimentos:

a) para dados publicados, em documentos oficiais, de diferentes instituições e em periódicos, disponibilizados nos sites ou em outra modalidade. Nessa etapa, foram utilizados os dados dos setores censitários: do Instituto Brasileiro de Geografia e Estatística (IBGE), da Prefeitura municipal de Campina Grande (https://campinagrande.pb.gov.br/), do setor de cadastro e da Superintendência de Trânsito e Transportes Públicos de Campina Grande (STTPhttps://sttp.campinagrande.pb.gov.br/).

Incorporaram-se, outros tipos de dados de trânsito/mobilidade urbana publicados pelos Departamentos de trânsito Nacional (DENATRAN) e do Estado da Paraíba (DETRAN PB), do Sistema de Registro Nacional de Veículos Automotores (RENAVAN/DETRAN), da Associação Brasileira de Empresas de Pesquisa (ABEP), sendo escolhidos alguns dos recortes geográficos da cidade de Campina Grande e da sua evolução temporal. 
b) para os dados coletados in loco, foram aplicados questionários com os passageiros na estação de integração de transporte coletivos de Campina Grande (Figura 2), com perguntas qualitativas e quantitativas referentes ao transporte coletivo da referida cidade.

Figura 2. Vista panorâmica do terminal de Integração de Transportes Coletivos de Campina Grande, PB.

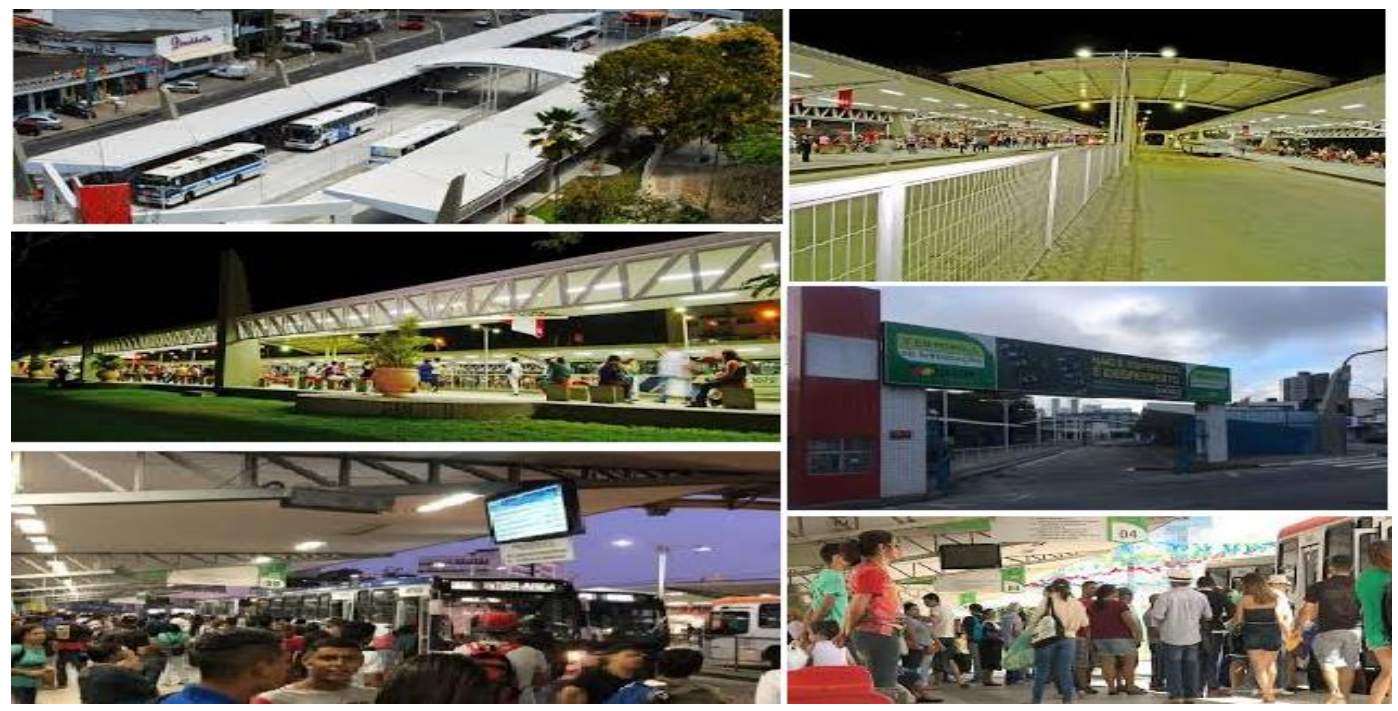

Fonte: Organizado pelo Google imagens: http://www.google.com.br/cidades/campinagrande, $\mathrm{PB}$

Os procedimentos metodológicos referentes ao tema mobilidade e transporte público, foram feitos mediante aplicação de questionário semiestruturado, com perguntas formuladas ao tema investigado, além da percepção sobre a qualidade dos serviços públicos de transportes.

Contabilizou-se como sendo automóveis, todos os veículos utilizados no transporte de pessoas e cargas, por serem meios de transportes trafegam nas vias urbanas, incluindo-se as motocicletas por ser um veiculo automotor dirigido por condutor em posição montada. Os ônibus ou micro-ônibus foram enquadrados, nessa classificação, como de transporte coletivo.

Os dados sobre o Plano de Mobilidade Urbana de Campina Grande (PLAMOBCG) foram disponibilizados pela Superintendência de Trânsito e Transportes Públicos de Campina Grande e pela Secretaria de Planejamento e Transparência da Prefeitura do Município.

As análises dos dados foram feitas, utilizando-se a estatística descritiva, agrupando-os em diferentes escalas (espacial e temporal), sendo os cálculos e as confecções de gráficas e tabelas, pela planilha eletrônica Excel. 


\section{RESULTADOS E DISCUSSÕES}

As profundas transformações das cidades influenciam o acesso da população de baixa renda, em especial, aos serviços públicos inerentes ao desenvolvimento urbano. Assim sendo, passa a ser notória a precariedade do sistema de mobilidade nacional, ao afetar os cidadãos mais carentes, os que mais precisam e por residir na periferia das médias e grandes cidades.

O tempo de deslocamento de casa ao trabalho tem se elevado substancialmente nas médias, grandes e/ou nas regiões metropolitanas brasileiras, durante a última década. Essa condição implica no bem-estar de cada indivíduo, embora essa diferença varie de acordo com as características socioeconômicas do trabalhador, do grau de instrução e de outros indicadores.

O crescimento desordenado das cidades reflete de forma negativa sobre os transportes urbanos e, consequentemente, para os que ali residem. A promoção da mobilidade urbana dá ênfase ao transporte público coletivo e não ao transporte individual.

As principais transformações demográficas no meio rural, mesmo no início deste século, mostram que o êxodo rural persiste em todo o território. 0 nível de escolaridade das pessoas é um importante determinante do êxodo rural, que também reforça a propensão dos mais jovens e das mulheres a deixarem o campo, em busca de melhores oportunidades de emprego, renda e estabilidade social.

O Brasil era um país rural, porque nesse espaço residia cerca de 80,0 \% da população. No entanto, a cada ano esse percentual se inverte e mais gente vem morar na cidade. Em Campina Grande, isso não é diferente e mais de 90\% das pessoas moram na zona urbana. A cidade parece ser a grande porta da felicidade e de realização de sonhos, porque as pessoas as buscam para estudar e trabalhar que a completa do ponto de vista pessoal ou renda.

As cidades se estabelecem e crescem sem planejamento urbano e, por isso, a mobilidade urbana exerce influência indireta no bem-estar, haja vista que a mobilidade urbana diz respeito às pessoas e não somente aos veículos, tais como: carros, ônibus, motos. Neste contexto, concorda-se com Ojima et al., (2013), o Brasil 
é um país com expansão expressiva da frota de veículos. Com isso, o dia-a-dia nas cidades se depara, com elevada frequência de congestionamentos.

O crescimento desordenado das cidades reflete de forma negativa sobre os transportes urbanos e, consequentemente, para todos os habitantes. A promoção da mobilidade urbana requer dar ênfase ao transporte público coletivo e não ao transporte individual, corroborando-se com Gomide (2003), que o conceito de exclusão social, estende-se o de pobreza para além da capacidade aquisitiva de bens e serviços.

Estas pessoas foram chegando às cidades e lá escolheram ficar, contudo a ocupação se deu de forma tão rápida, que tais localidades não tiveram tempo de se prepararem para recebê-las. As cidades se estabeleceram e cresceram sem planejamento urbano e, por isso, a mobilidade urbana exerce influência indireta no bem-estar.

Destaca-se, entretanto, que mobilidade urbana diz respeito às pessoas e não somente aos veículos, tais como: carros, ônibus, motos. Concorda-se com Ojima et al., (2015) que o Brasil é um país em estado avançado de transição urbana e tem passado por uma expressiva expansão de sua frota de veículos. Com isso, o dia-a-dia nas cidades se depara, cada vez mais, com uma sequência de congestionamentos, em virtude da ausência de investimentos significativos em transporte coletivo.

Para o sucesso das políticas públicas exitosas relacionadas ao desenvolvimento local, no âmbito do planejamento urbano, torna-se necessário estabelecer o perfil do recorte geográfico da cidade, levando-se em conta as necessidades da população, os principais motivos, duração, modo e frequência da mobilidade.

Antes de ser apresentado o perfil da mobilidade urbana da cidade de Campina Grande é importante apresentar o perfil da população, alguns interesses e características relevantes de seus cidadãos. Do contingente populacional de Campina Grande cerca de $20 \%$ são de idosos e há uma equidade relativa entre homens e mulheres. Cada domicílio da cidade abriga, em média, 3,5 pessoas, os 
bairros têm áreas territoriais de cerca de 2,0 km² de área territorial (IBGE, 2010), sendo os dez mais populosos mostrados na Figura 3.

Figura 3. Números de habitantes dos dez maiores bairros de Campina Grande-PB.

\section{Número de Habitantes (mil)}

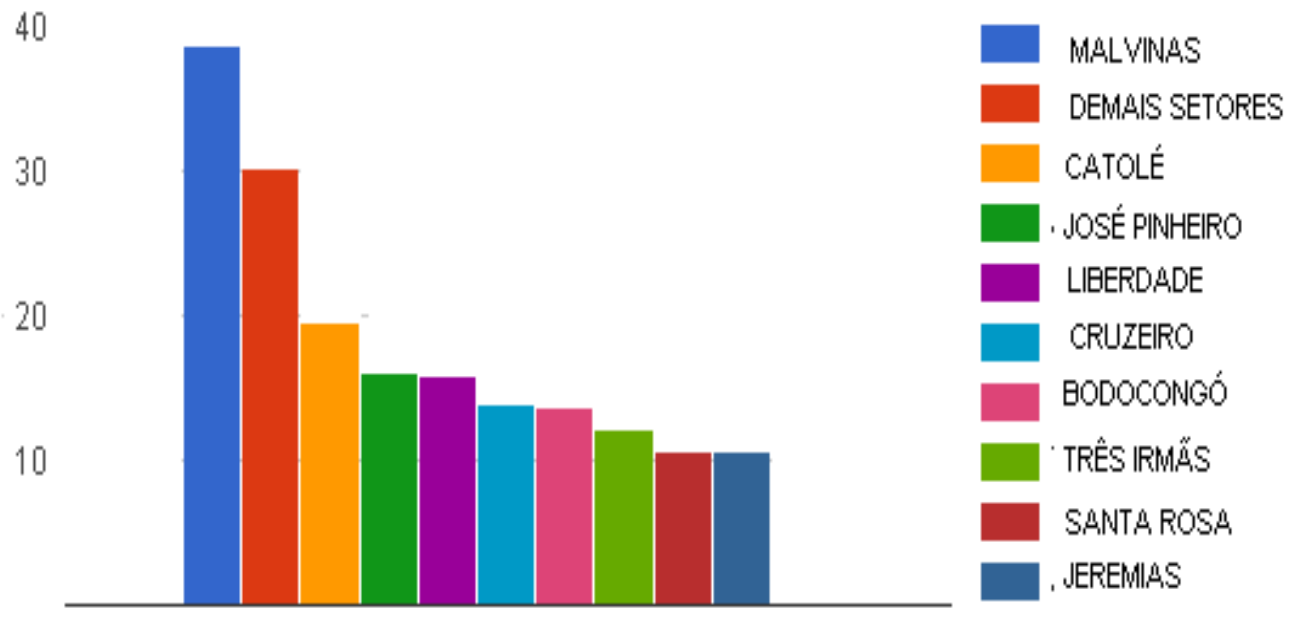

Bairros de Campina Grande-PB

Fonte: Censo Demográfico (IBGE 2010)

Registra-se que o item "DEMAIS SETORES" da Figura 3, corresponde a todos os outros setores que foram mencionados, além dos maiores (Malvinas, Catolé, José Pinheiro, Liberdade, Cruzeiro, Bodocongó, Três Irmãs, Santa Rosa e Jeremias).

O transporte coletivo é, sem dúvida, parte essencial de uma cidade e um dos principais problemas urbanos. Em Campina Grande esse item não é diferente, o ônibus é a primeira opção de transporte para o trabalho de mais de $40 \%$ da população trabalhadora.

Os resultados referentes às perguntas aos entrevistados, relacionadas aos principais problemas da cidade, são apresentados na Figura 4. 
Figura 4. Frequência relativa dos principais problemas no transporte público, em Campina Grande-PB.

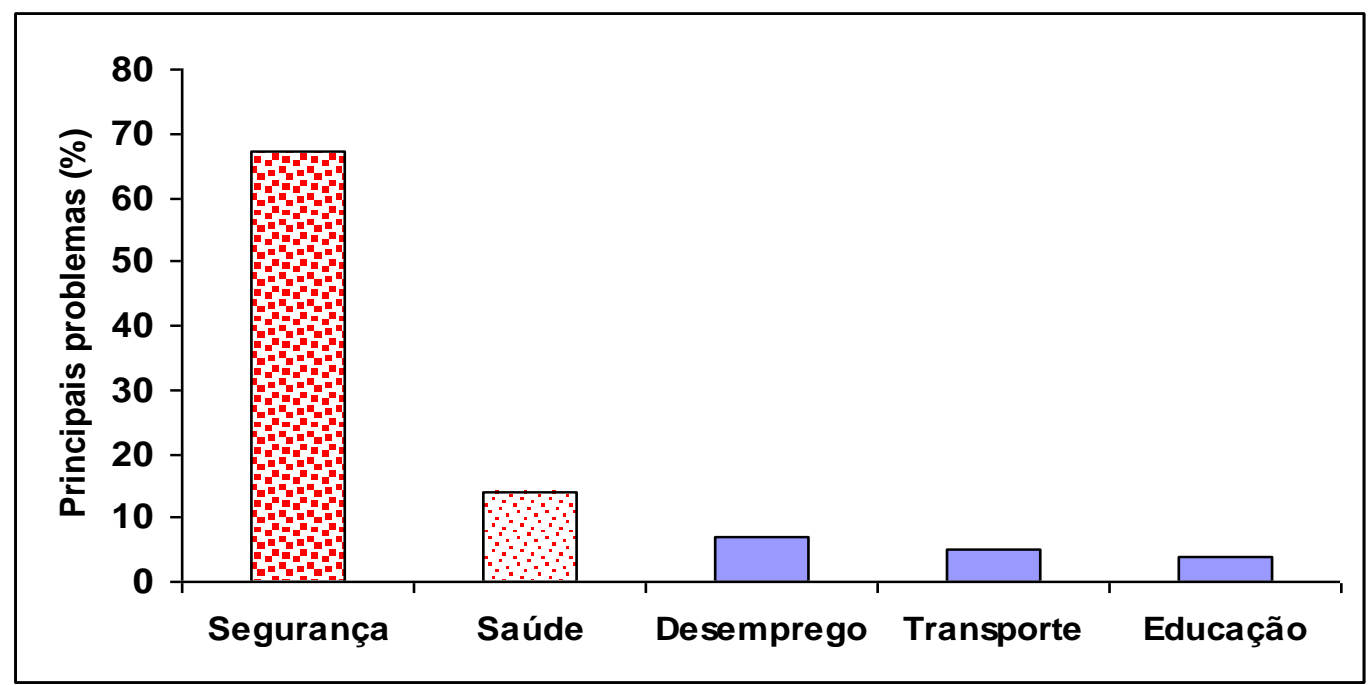

Fonte: Albuquerque e Almeida

A insegurança é um tema em pauta diária, especialmente, no interior dos coletivos e nos centros urbanos. 0 item segurança foi o primeiro a ser apontado pelos entrevistados, como o principal problema da cidade, seguido pela saúde, desemprego e transporte.

Observa-se (Figura 4) que cerca de 70,0 \% dos entrevistados, citaram a segurança como sendo o principal problema da cidade. Isso mostra, entretanto, que embora a agenda ambiental da cidade seja importante, para mudar a qualidade de vida das pessoas, para gerar emprego e renda e/ou pela oportunidade de crescer nos níveis educacionais, o item segurança foi o mais citado.

As inovações tecnológicas não alcançam a população de um dia para outro, mas de forma gradual e lenta. Garantir a mobilidade das pessoas nas cidades traz benefícios econômicos e de qualidade de vida, tanto do ponto de vista individual quanto coletivo.

A Figura 5 apresenta os percentuais dos entrevistados que utilizam ou não o transporte coletivo na cidade de Campina Grande, PB.

O universo de usuário de transporte coletivo predomina o do sexo feminino, com 61,0 \%. Com relação frequência de utilização, observa-se que cerca de 40,0\% usam o ônibus, como principal meio de transporte. Já, 33,0 \% deixaram de utilizar e 22,0\% relataram ter diminuído essa opção de transporte. 
Figura 5. Frequência de utilização do Transportes Coletivos em Campina Grande, PB.

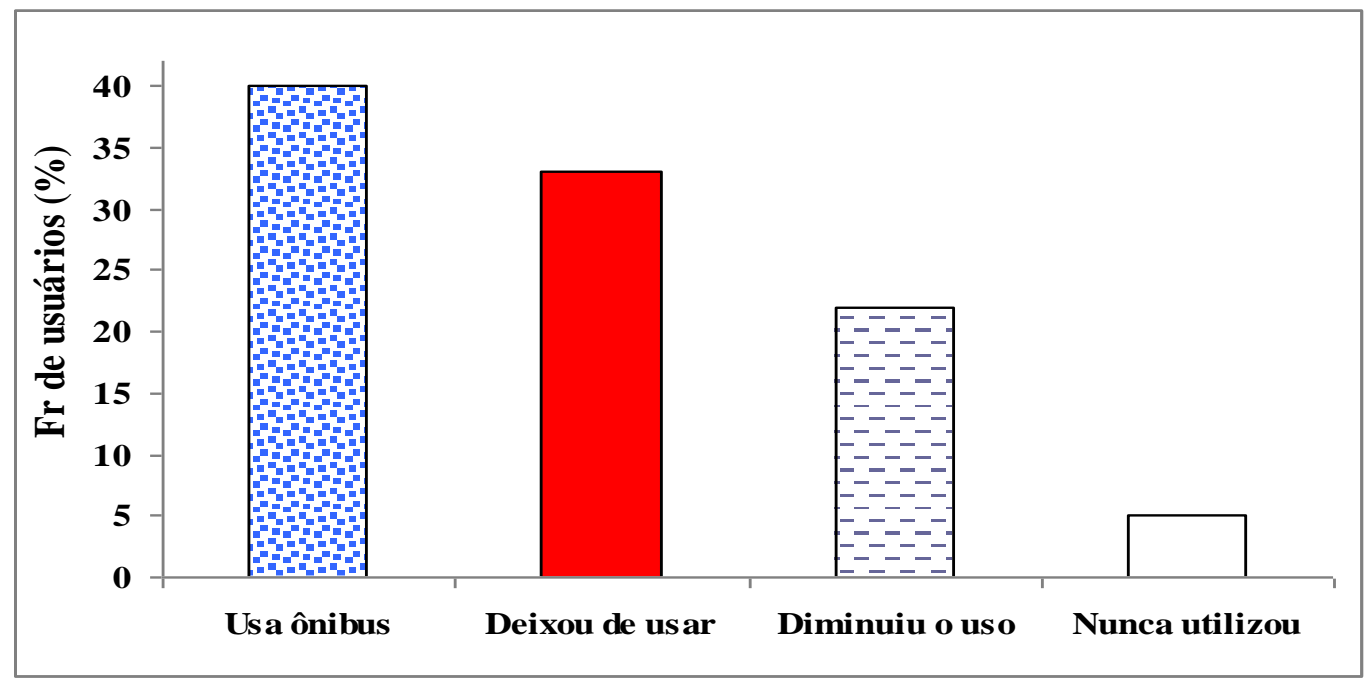

Fonte: Albuquerque e Almeida

Isso mostra, portanto, que uma grande parcela da população usuária, migrou para outro tipo de transporte, como mostra a Figura 6.

Figura 6. Frequência dos usuários do transporte coletivo de Campina Grande, PB, que migraram para outros tipos de transporte.

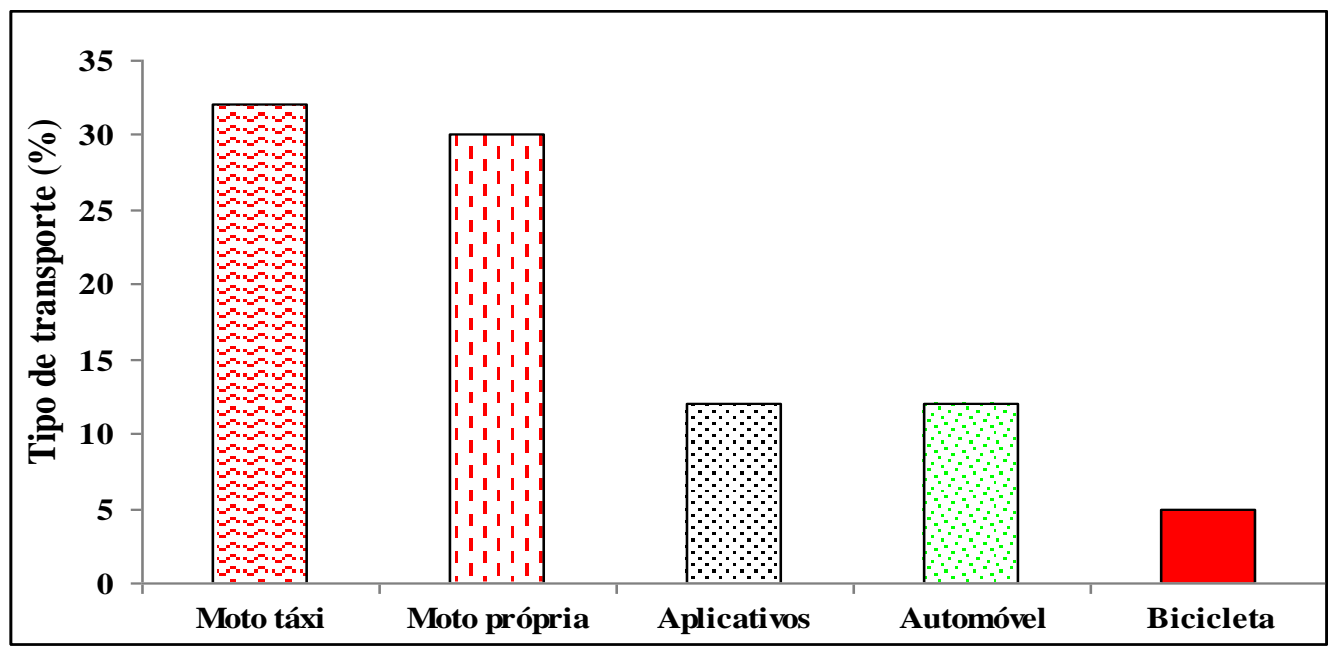

Fonte: Albuquerque e Almeida

É notório o crescente índice de motorização de veículos de duas rodas, especificamente, a motocicleta, sendo utilizada não somente para o esporte e lazer, 
mas com um meio de transporte mais econômico, inclusive como um gerador de emprego (moto-táxi).

Essa tendência é constata aqui em Campina Grande, comprovada com o elevado percentual $(60,0 \%)$ dos usuários de ônibus que migraram para a motocicleta, seja adquirindo a sua própria moto ou utilizando-a como taxi (moto taxi). A opção pelo veiculo motorizado de duas rodas, se deve a rapidez, ao deslocamento ser ponto a ponto e a redução do tempo de espera, além de evitar o caminhar até o ponto de parada do ônibus.

Destaca-se, entretanto, que a oferta inadequada de transporte coletivo, prejudica uma parcela da população mais pobre, estimula o uso do transporte individual, em detrimento ao de ônibus, ocasionando aumenta os níveis de poluição e congestionamentos. Condições esses que estimulam, ainda mais, o uso da motocicleta.

Os elevados percentuais de opção de migração do ônibus para motocicleta (Figura 6), em detrimento ao uso de transporte coletivo e não motorizado (bicicleta), vão de encontro ao que preconiza a nova Lei de Mobilidade Urbana. Não se trato de algo isolado, porque tendências semelhantes ocorrem entre outras regiões corroborando com os resultados do IPEA (2019), ao quantificou uma participação média de $64,0 \%$ de motos nas frotas municipais na região Norte.

Os indicativos apresentados nas Figuras 5 e 6 mostram não ser possível pensar no meio urbano sem pensar no trânsito. Certamente, o trânsito provoca impacto tanto na qualidade de vida das pessoas quanto no meio ambiente urbano.

Como a mobilidade está relacionada aos deslocamentos (viagens) da população no espaço urbano, quem reside em bairros mais periféricos, mais distantes, gasta muito mais tempo para realizar suas atividades. Parece lógico e real concordar com Cardoso (2008), que para sobreviver na cidade, em especial, as pessoas de baixa renda, obrigam-se a fazer uma infinidade de deslocamentos para atingir os destinos desejados. 
Como o transporte coletivo é um meio para atingir determinados fins, seja ele o trabalho, a escola, dentre outros, o deslocamento das pessoas se torna um ponto estratégico para o desenvolvimento econômico e social.

Para se ter uma ideia do número do usuário do transporte coletivo em Campina Grande, escolheu-se alguns bairros que fazem partem das zonas geográficas da cidade (Figura 7), os números de habitantes, cujas linhas de ônibus integram com o terminal de Integração de Transportes Coletivos mostrado na Figura 2.

0 transporte coletivo é, sem dúvida, parte essencial de uma cidade e um dos principais problemas urbanos. Em Campina Grande esse tema não é diferente, porque o ônibus é o meio de locomoção primário da cidade, ou seja, uma forma de garantir o direito de ir e vir dos cidadãos.

A atividade de transporte e o desenvolvimento econômico estão sempre associados, uma vez que os transportes públicos urbanos são serviços essenciais, responsáveis pela movimentação de pessoas e mercadorias nas cidades.

Figura 7. Número médio de usuários por zonas geográficas de Campina Grande, PB.

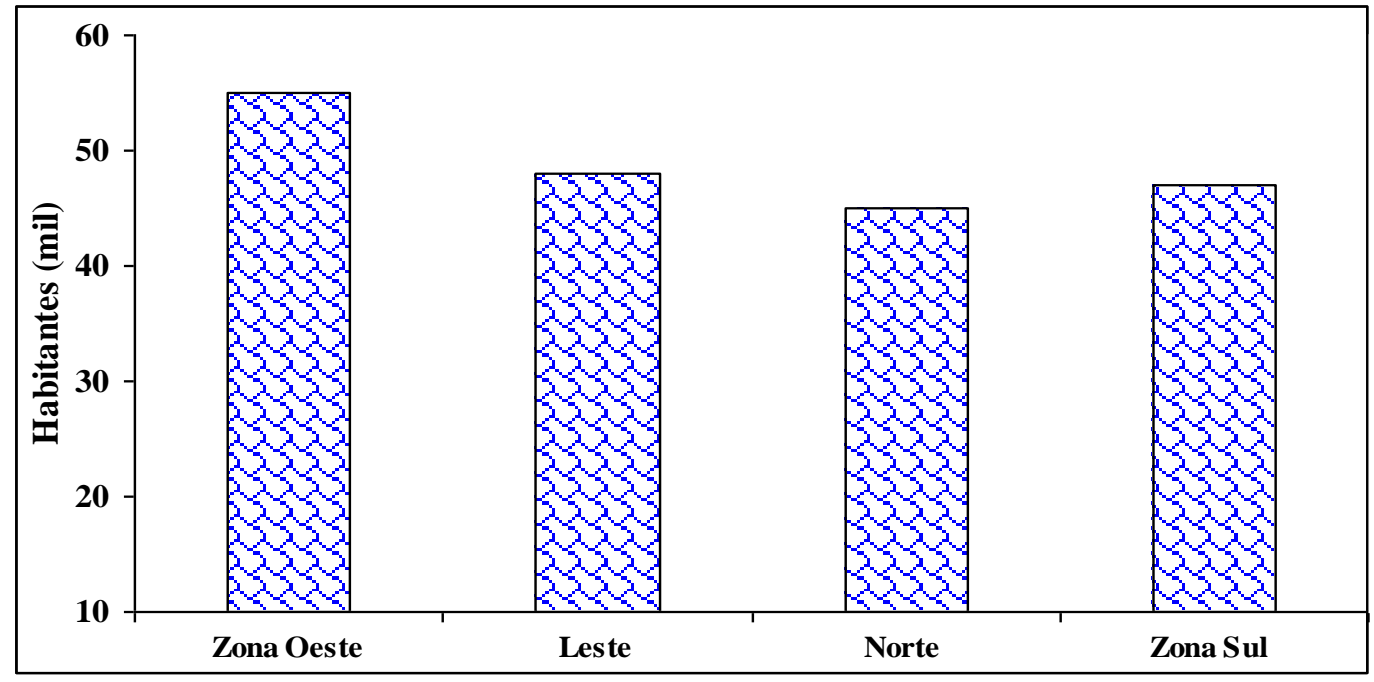

Fonte: Censo Demográfico (IBGE 2010)

Concorda-se com Araujo et al., (211), que o transporte coletivo é um serviço essencial nas cidades, pois democratiza a mobilidade, reduz congestionamento e os níveis de poluição, além de minimizar a necessidade de construção de vias e estacionamentos. 
Os ônibus são modalidades de transporte público coletivo nos quais os passageiros não são proprietários e, por isso, são serviços terceirizados e executadas majoritariamente, por empress privadas, por concessão pública.

No contexto geral, concorda-se com a CNT (2017), da dificuldade de encontrar dados e informações confiáveis que permitam monitorar a mobilidade urbana no Brasil, mesmo após anos de vigência da Lei no 12.587/2012, que define a Política Nacional de Mobilidade Urbana.

\section{A evolução temporal da frota de veículos particulares de Campina Grande}

O número de carros no Brasil, não pára de crescer. Com base nos registros do Departamento Nacional de Trânsito e do Instituto Brasileiro de Geografia e Estatística, as dez cidades com mais carro por habitante, nove localizam-se na região Sudeste. São Caetano do Sul, SP, é a campeã e tem cerca de 100 mil veículos para uma população de 156 mil habitantes, ou seja, uma média de dois veículos para cada três pessoas.

O número de veiculos automotores (carros e motos), em Campina Grande, vem crescendo exponencialmente, como mostra a evolução de temporal apresentada na Figura 6.

Verifica-se que, nesses últimos dez anos, os números de carros e motocicletas, nessa cidade, dobraram. Passaram, respectivamente, de cerca de 60 para 120 mil carros e de 30 para 60 mil motos. Acumulando-se, contabiliza-se que há mais de 282 mil veiculos automotores (carros e motos), ou seja, uma proporção de um veículo para cada 2,25 habitantes.

Figura 6. Evolução temporal da frota de veículos automotores (carros e motos), em Campina Grande, PB. 


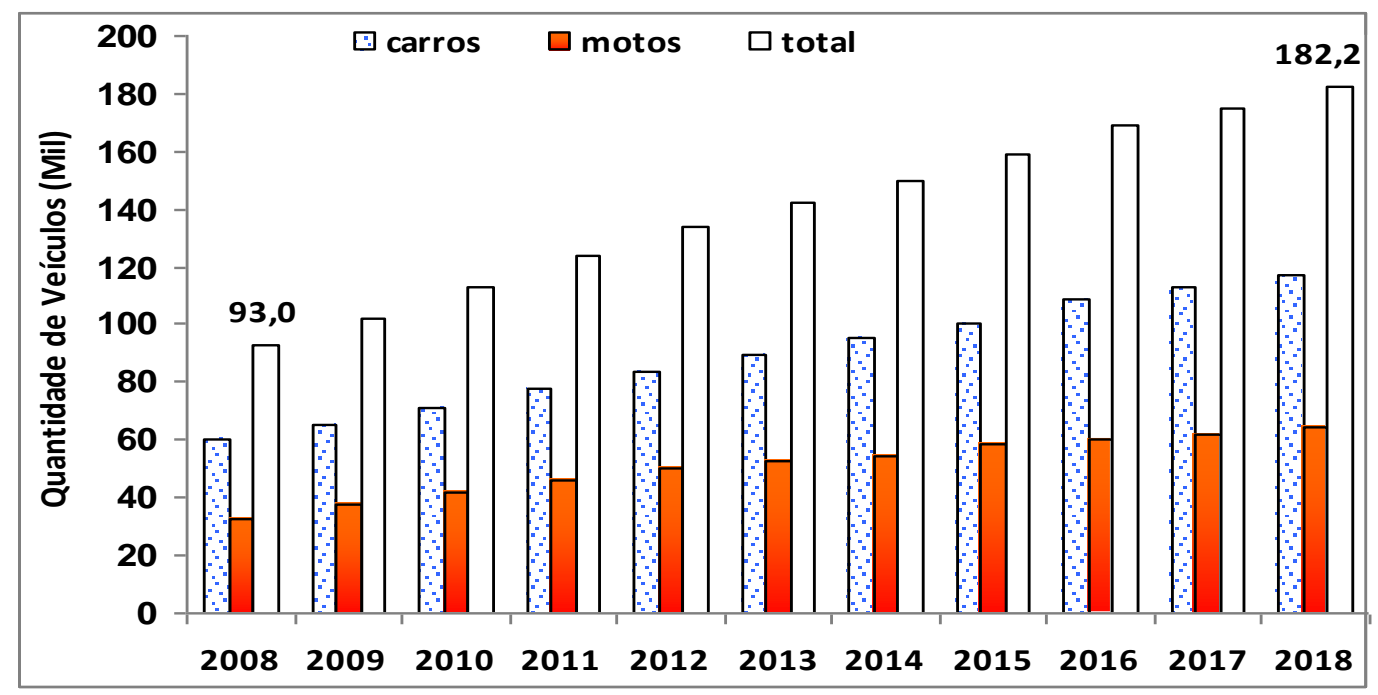

Fonte: Superintência de Transito e Transporte de Campina (2020)

Analisando-se o crescimento da frota de veículos em Campina Grande (Figura 6), percebe-se que os problemas de transito tendem a crescer, porque a melhoraria na mobilidade requer espaço, cada vez maior, nas áreas centrais de circulação e estacionamentos. Assim, a ocupação do espaço urbano pelo transporte, precisa ser ampliada.

A mobilidade urbana tem se destacado como um dos problemas mais presentes e incômodos na vida cotidiana. No Brasil e em muitos outros países, o deslocamento das pessoas pelas áreas urbanas está cada vez mais difícil. 0 número de automóveis parece exceder o espaço disponível nas ruas, uma vez que o aumento da frota de veículos não acompanha na mesma proporção a expansão da malha viária,

O número de carros não para de crescer no país, e registra-se uma frota nacional de um automóvel para cada 4,4 habitantes, a cerca de dez anos atrás essa proporção era quase o dobro. Os registros do Departamento Nacional de Trânsito (Denatran) e do Instituto Brasileiro de Geografia e Estatística (IBGE), revelam que em 2013, por exemplo, das dez cidades com mais carros por habitante, nove estão na região Sudeste, cuja campeã é São Caetano do Sul, que tinha uma média de dois veículos para cada três pessoas

Para averiguar essa relação, escolheu-se as cidades nordestinas de porte médio, cujas relações entre quantitativos de habitantes e de veículos e da sua relação 
entre si são apresentadas na Figura 7. 0 indicador oscila de zero a 1, e quanto mais próximo do máximo, maior é o número de veículos nas cidades analisadas.

Figura 7. Relação entre as quantidades de habitantes e veículos, para cidades de porte médio dos Estados da Paraíba, Pernambuco e Alagoas.

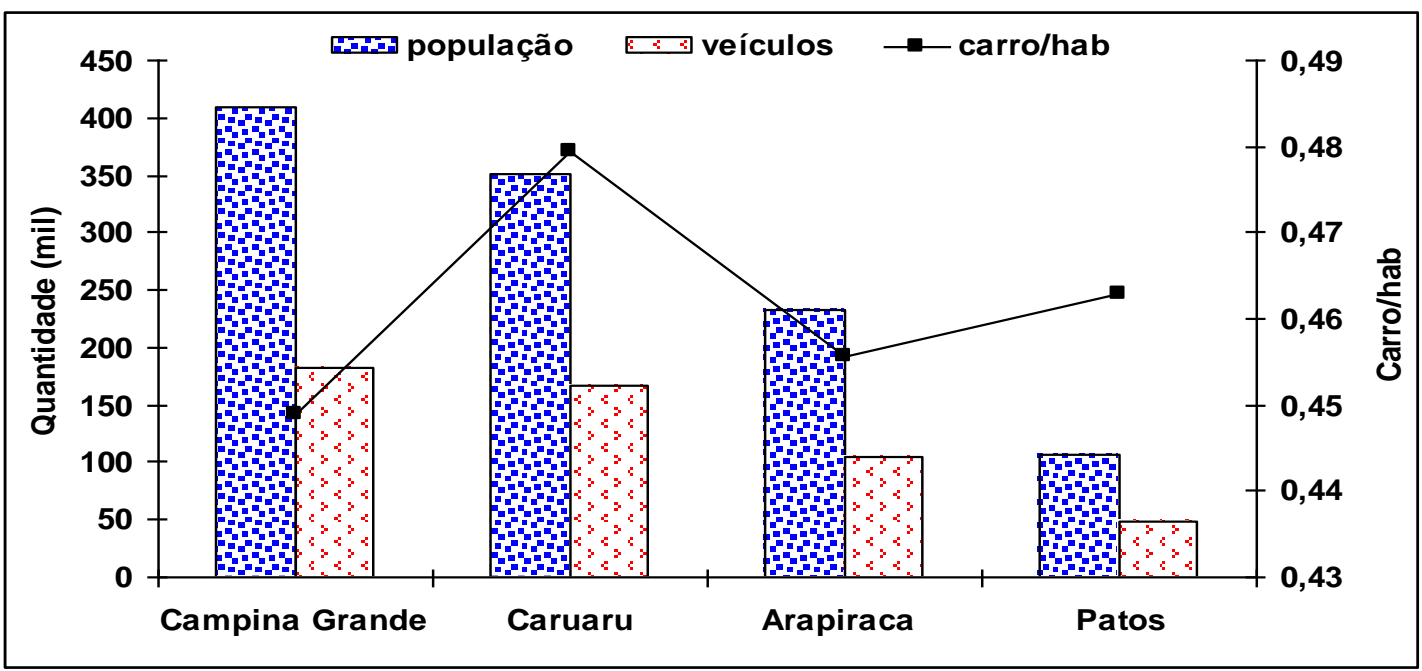

Fonte: Organizado com dados disponíveis: www.denatran.gov.br

Os indicadores da Figura 7 mostram que as relações entre o número de carros e de habitantes são muito próximas, cujo índice médio é de 0,46 veículo por habitante. Embora Campina Grande seja a cidade mais populosa, tem a menor relação $(0,44)$ e Caruaru a maior $(0,47)$. Esses resultados são compatíveis com os citados pela CNT (2017), cujos índices são de 0,40 para as cidades de Natal, RN, e João Pessoa, PB e de 0,48 para Teresina, PI.

Numa análise comparativa entre o número de habitantes e de carros (Figura 7), constata-se que embora em Campina Grande esses quantitativos sejam cerca de quatro vezes maiores que os de Patos, a referida relação é muito próxima $(2,25$ e 2,18), respectivamente, o equivalente a 2,25 e 2,18 pessoas para um automóvel.

Há uma tendência generalizada tanto na zona urbana quanto na rural, pelo uso da motocicleta, haja vista ser esse meio de transporte mais rápido, vantajoso para realizar o seu deslocamento e por ser compatível com a sua renda disponível. Condições essas comprovadas no Registro Nacional de Veículos Automotores (RENAVAM), entre os anos de 2000 e 2010, quando a frota brasileira de automóveis aumentou 83,55\% e o de motos, $284,4 \%$. 
Diante disto, a Figura 8 apresenta um estudo comparativo entre os números de carros e de motos existentes em Campina Grande, comparados com os de outras cidades de porte médio dos Estados da Paraíba, Pernambuco e Alagoas, e das relações entre si, cujos indicadores variam de zero a um. Os quantitativos maiores de motos que os de carros, nas cidades de Arapiraca, AL, e Patos, PB, mostram a opção do usuário por esse meio de transporte nessas duas cidades.

Figura 8. Comparação dos números de carros e motos de Campina Grande com os das cidades de porte médio: Caruaru, PE, Arapiraca, AL e Patos, PB.

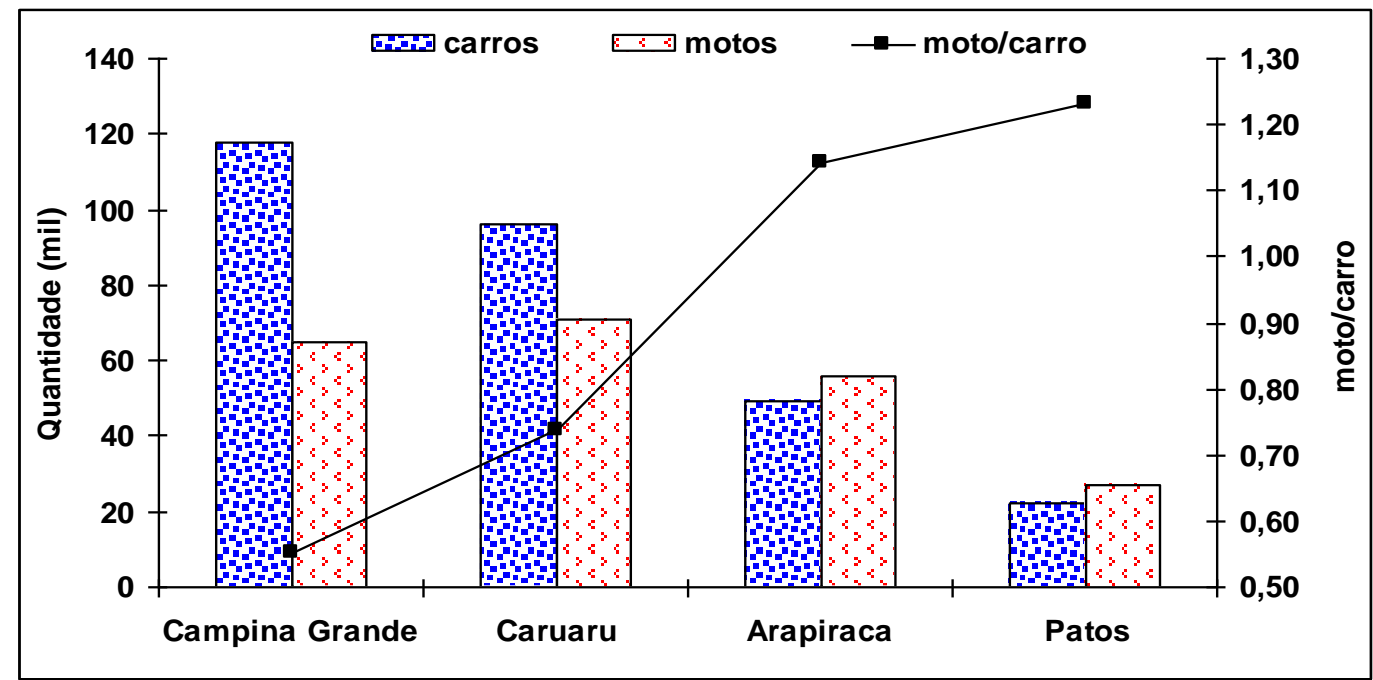

Fonte: Organizado com dados disponível em: www.denatran.gov.br

Quando se compara a frota de carro com a de moto, observa-se (Figura 8) que o quantitativo de motocicleta, nessas quatro cidades, já é maior em Arapiraca e em Patos, enquanto que Campina Grande, mesmo tendo um número maior de motos, esse meio de transporte de duas rodas, representa $55,1 \%$ da de carros.

Esses quantitativos sempre crescentes do transporte motorizado contrariam o direito ao acesso equitativo a cidade, proposto pela Lei $\mathrm{n}^{-}$12.587, da Política Nacional de Mobilidade Urbana, que prioriza o transporte não motorizado e ao coletivo.

Destaca-se, entretanto, que a opção pela motocicleta se deve, em grande parte, a facilidade de aquisição, o baixo custo de manutenção, associada às 
deficiências do transporte coletivo, que faz do uso da moto um meio de transporte propício para o trabalho, na maioria das vezes informal.

Concorda-se com as afirmações feitas por Queiroz e Oliveira (2000) e Barros et al., (2003) que, um dos principais motivos para o alto número de acidentes com motociclistas está relacionado ao aumento da frota. A sua utilização como instrumento de trabalho tem sido referida por esses autores como possível causa para o aumento do número de vítimas de motociclistas.

A Figura 9 sumariza e exemplifica a evolução temporal do número de acidentes automobilísticos, em Campina Grande, na sua maioria, oriundos de motocicletas. Destaca-se, entretanto, que somente com a implantação da fiscalização eletrônica, monitoramento viário, campanhas educativas e outras medidas adotadas pela STTP, a partir de 2016, constataram-se o declínio de acidentados.

Figura 9. Evolução temporal de ocorrências de atropelamentos de pedestres em Campina Grande, PB.

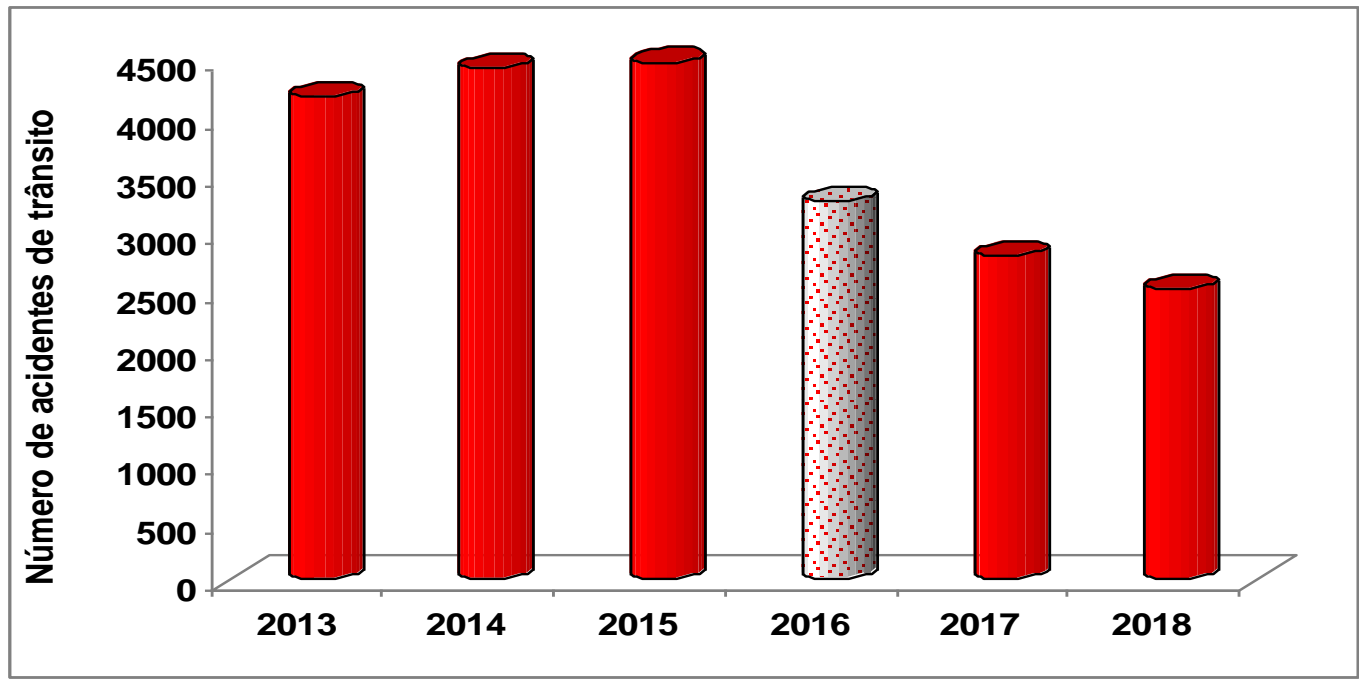

Fonte: Superintendência de Trânsito e Transportes Públicos (STTP, 2020)

Destaca-se, entretanto que os motociclistas são mais vulneráveis a se ferirem em colisão com veículos maiores. Se 61,0\% dos usuários de motos (Figura 9) são do sexo feminino e com base nos relatos de Oliveira e Sousa (2012), que as mulheres têm mais chances de sofrer lesões, credita-se que o maior percentual seja de motoqueiras. 


\section{CONCLUSÕES}

A Lei de Mobilidade Urbana sozinha não é suficiente para garantir sustentabilidade, ampliar investimento urbano, reduzir os congestionamentos e a melhoria na qualidade do serviço de transporte de Campina Grande.

O transporte coletivo urbano na referida cidade é a primeira opção de mobilidade para as pessoas enquadradas nas classes sociais de baixo poder aquisitivo e níveis de escolaridade, mas precisa ser estruturada e planejada, a fim de evitar que a expansão contribua para agravar a mobilidade.

A cidade já se depara dia-a-dia, com os elevados congestionamentos e mais da metade dos usuários do ônibus migraram para a motocicleta, comprometendo a sustentabilidade e, por consequência, a qualidade de vida da polução, em virtude dos crescentes números de acidentes.

O quantitativo de motos já é maior que o de carros, especialmente, nas pequenas cidades, por ser um meio de transporte mais rápido e mais acessível à população.

Como a maior demanda de mobilidade é para o centro da cidade, sugere-se planejar a expansão comercial e de serviços para os bairros.

Embora a mobilidade urbana não seja somente em relação aos carros, a quantidade de motocicleta existentes nas cidades de Patos, PB, e Arapiraca, AL, já supera a de carros, o que demonstra uma tendência deste movimento social para cidades com o mesmo porte de Campina Grande-PB.

Ações de educação no trânsito, sinalização e corredores de trânsito resultam não somente na segurança viária, mas na diminuição de custos sociais de acidentes de trânsito, na melhoria da acessibilidade e mobilidade dos pedestres. 


\section{REFERÊNCIAS}

BARROS, A. J. D.; AMARAL, R. L.; OLIVEIRA, M. S. B.; LIMA, S. C.; GONÇALVES, E. V. Motor vehicle accidents resulting in injuries: underreporting, characteristics, and case fatality rate1, v.9, n.4:, p. 979-86, 2003.

BRASIL. Ministério das cidades. Mobilidade e política urbana: subsídios para uma gestão integrada. Coordenação de Lia Bergman e Nidia Inês Albesa de Rabi. Rio de Janeiro: IBAM; Ministério das Cidades, 2005, 52 p.

BRASIL. LEI 12.587/2012 - Política Nacional de Mobilidade Urbana como Instrumento de Efetivação do Direito à Cidade. Diário Oficial da União, Brasília, 2012, 24p.

CARDOSO, C. E. P. Análise do transporte coletivo urbano sob a ótica dos riscos e carências sociais. Tese de doutorado, Programa de Pós-graduação em Serviço Social, Pontifícia Universidade Católica de São Paulo, São Paulo, SP, 2008, 139fls.

CARVALHO, C. H. R. Emissões relativas de poluentes do transporte urbano. Boletim regional, urbano e ambiental, n.5, p. 123-139, 2011

CARVALHO, C. H. R DESAFIOS DA MOBILIDADE URBANA NO BRASIL. Instituto de Pesquisa Econômica Aplicada. Brasília: Rio de Janeiro, 2016, 30 p.

CONFEDERAÇÃO NACIONAL DO TRANSPORTE (CNT). Pesquisa mobilidade da população urbana 2017. Transporte, Associação Nacional das Empresas de Transportes Urbanos. Brasília: CNT: NTU, 2017, 96p

CRAICE, C. A mobilidade populacional e sua relação com o ambiente: breve panorama dos principais debates. Idéias - Rev. Inst. Filos. Ciênc. Hum. UNICAMP, v.6, n.1, p. 63-85, 2015

IPEA. A mobilidade urbana no Brasil: percepções de sua população. Texto para discussão- Instituto de Pesquisa Econômica Aplicada (IPEA), Brasília, DF, 2019, 62p. GOMIDE, A. A. Transporte urbano e inclusão social: elementos para políticas públicas. Instituto de Pesquisa Econômica Aplicada. [Texto para discussão, № 960]. Brasília, DF: IPEA, 2003.

LÉVY, J. Os novos espaços da mobilidade. Geographia. Rio de Janeiro, no 6 , p. 75-93, 2001. 
LITMAN, T. Evaluating Transportation Land Use Impacts. Originally published as "Land Use Impact Costs of Transportation". World Transport Policy \& Practice, vol. 1, no. 4, pp. 9-16, 1995.

MARICATO, E. A cidade e o automóvel. Revista Ciência e ambiente, São Paulo, n. 37, p.5-12, 2008.

MARTINS, M. F., VASCONCELOS, A. C. F.; SALLES, M. C. T. Plano de Mobilidade Urbana do Município de Campina Grande: uma análise à luz da sustentabilidade urbana. Revista de Gestao Ambiental e Sustentabilidade, v. 6, n. 2., p. 42-58, 2017

MOURA, R.; PEGO, B. Aglomerações urbanas no Brasil e na América do sul: trajetórias e novas configurações. Texto para discussão/Instituto de Pesquisa Econômica Aplicada (IPEA), Brasília: Rio de Janeiro, 76p, 2016.

OJIMA, R.; MARANDOLA Jr., E. Mobilidade populacional e um novo significado para as cidades: dispersão urbana e reflexiva na dinâmica regional não metropolitana. Revista Brasileira de Estudos Urbanos e Regionais, ANPUR, Rio de Janeiro, v. 14, n. $2,2012$.

OJIMA, R.; MONTEIRO, F. F.; NASCIMENTO, T. C. L. Deslocamentos pendulares, reestruturação produtiva e o consumo do espaço na urbanização brasileira: explorando o tempo de deslocamento casa-trabalho. Revista Paranaense de Desenvolvimento, Curitiba, v.36, n.128, p.133-147, 2015

OLIVEIRA, N. L. B, SOUSA, R.M. C. Risk for injuries among motorcyclists involved in traffic incidents. Rev. Esc Enferm USP, v. 46, n. 5, p. 1132-9, 2012

QUEIROZ, M. S.; OLIVEIRA, P. C. P. Traffic accidents: a qualitative approach from Campinas, São Paulo, Brazil. Cad. Saúde Pública, v. 18, n. 5, p. 1179-87, 2000

SILVA, N. O.; FREIRE, F. S.; SANTOS, S. S. Políticas Públicas de Mobilidade Urbana: a percepção do usuário do transporte público no Distrito Federal. Revista de Pesquisa em Políticas Públicas, n. 2, 25 p, 2020. 
SEDU PR - Secretaria Especial de Desenvolvimento Urbano da Presidência da República. Grupo Executivo de Transporte Urbano. Motivações que regem o novo perfil de deslocamento da população urbana brasileira: pesquisa de imagem e opinião sobre os transportes urbanos. Relatório Final. Brasília, dezembro de 2002. VASCONCELLOS, E. A. A cidade, o transporte e o trânsito. São Paulo: Pró Livros, 2005, 31 pp.

Recebido em: 15/09/2021

Aprovado em: 30/09/2021

Publicado em: 08/10/2021 